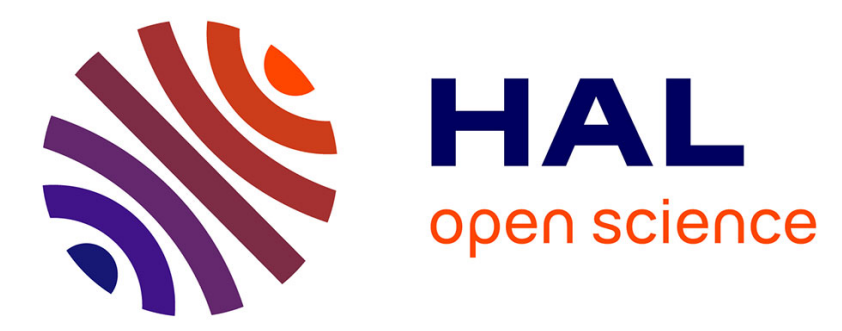

\title{
Catalytic converter modeling for optimal gasoline-HEV energy management
}

Pierre Michel, Alain Charlet, Guillaume Colin, Yann Chamaillard, Gérard Bloch, Cédric Nouillant

\section{- To cite this version:}

Pierre Michel, Alain Charlet, Guillaume Colin, Yann Chamaillard, Gérard Bloch, et al.. Catalytic converter modeling for optimal gasoline-HEV energy management. 19th IFAC World Congress, IFAC'14, Aug 2014, Cape Town, South Africa. pp.6636-6641. hal-01062316

\section{HAL Id: hal-01062316 https://hal.science/hal-01062316}

Submitted on 9 Sep 2014

HAL is a multi-disciplinary open access archive for the deposit and dissemination of scientific research documents, whether they are published or not. The documents may come from teaching and research institutions in France or abroad, or from public or private research centers.
L'archive ouverte pluridisciplinaire HAL, est destinée au dépôt et à la diffusion de documents scientifiques de niveau recherche, publiés ou non, émanant des établissements d'enseignement et de recherche français ou étrangers, des laboratoires publics ou privés. 


\title{
Catalytic converter modeling for optimal gasoline-HEV energy management
}

\author{
Pierre Michel*,** Alain Charlet* Guillaume Colin* \\ Yann Chamaillard ${ }^{*}$ Gérard Bloch ${ }^{* * *}$ Cédric Nouillant ${ }^{* *}$ \\ * Laboratoire PRISME, Université d'Orléans \\ ** PSA Peugeot Citroën, Direction Recherche Innovation 8 \\ Technologies Avancées (DRIA) \\ *** Centre de Recherche en Automatique de Nancy (CRAN), \\ Université de Lorraine, CNRS
}

\begin{abstract}
A simple multi-0D model of a 3-Way Catalytic Converter (3WCC) is built from physical equations, integrating the temperature dynamics and a pollutant emission conversion map. The validated model involves complexity and performances suitable to be integrated in a high fidelity powertrain model of a gasoline-Hybrid Electric Vehicle (HEV). Next, a pollutant constrained optimal energy management is derived from the Pontryagin Minimum Principle. The approach allows the joint minimization of pollution and fuel consumption with only one parameter to tune, by considering all the standardized pollutant emissions. The proposed strategy significantly reduces pollutant emissions with only a slight fuel consumption increase. Using a complex HEV model shows the feasibility of the pollution constraint integration in on-line energy management.
\end{abstract}

Keywords: Hybrid vehicle, pollutant emission, catalytic converter (3WCC) modeling, energy management system, optimal control

\section{INTRODUCTION}

The electrical hybridization of a conventional car can decrease the fuel consumption by various means: recuperative breaking, Stop \& Start or energy management. The energy management strategy impacts the Hybrid Electric Vehicle (HEV) operation particularly in terms of pollutant emissions. Thus, a strategy aiming at reducing the fuel consumption while respecting pollutant emissions standards has to consider the 3-Way Catalytic Converter (3WCC). For a gasoline engine, the 3WCC temperature dynamics plays a key role in pollutant emission.

Historically, the optimal energy management strategies were built to ensure a minimal fuel consumption, for a trip known a priori, most often a driving cycle. Usually this is done by using either Dynamic Programming (DP), derived from Bellman's principle, Bellman (1956), or the Pontryagin Minimum Principle (PMP), Pontryagin (1962), from quasistatic HEV models. The only dynamics considered in these off-line strategies concerns the electrical battery State Of Charge (SOC).

More recent off-line strategies take into account additional considerations, such as pollutant emissions.

- The first one minimizes the tradeoff between engine pollutant emission and fuel consumption flow rates with the PMP method, see Grondin et al. (2011) and Millo et al. (2011) for diesel-HEV. PMP or DP approaches were compared in Michel et al. (2012) to solve the minimization problem for gasoline-HEV, with similar results.
- A second idea is to minimize a mixed post-3WCC or vehicle pollutant emissions/fuel consumption masses with the PMP method, see Serrao et al. (2013).

- A third strategy integrates the $3 \mathrm{WCC}$ temperature as a second state in the optimization problem for the latter strategy, see Serrao et al. (2013), Chasse et al. (2010), Tate et al. (2010) and Kum et al. (2008). This approach is motivated by the crucial influence of the 3WCC temperature on the conversion. In Michel et al. (2013), we showed empirically that the second strategy yields better results than the third.

Such off-line optimal energy management strategies are usually set up to establish a reference, and to develop and evaluate the on-line strategies. They must then take into account accurately the real powertrain of cars.

The work presented here proposes a generic pollutantconstrained energy management strategy for a gasoline HEV modeled with a high fidelity level. A PSA Peugeot Citroën model was used. As the pollutant constraint has only recently been considered in energy management, this model does not include the 3WCC. Thus, the 3WCC has been modeled leading to a control-oriented model, which is simultaneously accurate and computationally inexpensive. The first minor contribution of the present study is the use of a multi-0D 3WCC model instead of a 0D model as in the third strategy cited above. The major contribution is the introduction of one-parameter performance index in the optimization method ensuring a simple minimization of all the pollutant species defined in the standards.

The rest of the paper is organized as follows. The next section proposes a multi-0D 3WCC model, which is ac- 
curate but sufficiently simple to be included in the HEV model. In section 3 , the model is identified and validated from test bench experiments. Then, section 4 describes the energy management strategy optimizing both the fuel consumption and pollutant emissions. This optimal strategy includes the $3 \mathrm{WCC}$ temperature dynamics and the oneparameter performance index. The results are presented in section 5 , before giving some conclusions.

\section{3WCC MODEL}

The 3WCC model is a multi-0D model based on the physical equations. Basically, the physical phenomena are described by partial differential equations involving the three space dimensions. These equations are simplified by considering only the longitudinal dimension and discretizing this variable. Thus the model includes several zones that exchange heat with one another. A zone represents a radial slice of the $3 \mathrm{WCC}$ monolith which is assumed to be cylindrical. The zones are numbered in increasing order, with index $x$, from the entry zone 1 .

The model is based on the following assumptions:

- the heat transfers between the solids and the ambient air are negligible compared with the other transfers,

- the same gas flow rate goes through the 3WCC and its zones, the exhaust gas flow rate $\dot{m}_{g}$.

The model equations are first presented, before summarizing the variables and parameters and their type.

\section{$2.10 D$ modeling}

A monolith zone is considered as a solid mass containing exhaust gas. From the heat equation, the evolution for the current zone $x$ of the solid $T_{s x}$ and gas $T_{g x}$ temperatures can be deduced as:

$$
\Delta T_{s x}=\frac{\sum \Delta Q_{(s)(g)}}{m_{s x} C_{p}}
$$

and

$$
\Delta T_{g x}=\frac{\sum \Delta Q_{(s)(g)}}{m_{g x} C_{v}},
$$

where $Q_{(s)(g)}$ are the heat transfers, and, respectively for the solid and gas, $m_{s x}$ and $m_{g x}$ are the masses and $C_{p}$ and $C_{v}$ are the specific heat capacities. Assuming that the gas is ideal, the mass $m_{g x}$ can be given by:

$$
m_{g x}=\frac{\rho V_{g x}}{T_{g x} T_{0}},
$$

where $\rho$ is the air density at $0^{\circ} C, V_{g x}$ the gas volume in the zone and $T_{0}$ is $273^{\circ} \mathrm{C}$.

Different types of heat transfer $Q_{(s)(g)}$ influence the evolution of the temperatures:

- convection between solid and gas inside the zone $x$ :

$$
Q_{s g x}=S_{s g} c_{\text {conv }}\left(T_{g x}-T_{s x}\right),
$$

where $S_{s g}$ is the surface between solid and gas and $c_{c o n v}$ the convective coefficient,

- conduction between the solids of two successive zones:

$$
Q_{s x, x+1}=\frac{S_{x, x+1} \lambda}{d_{x, x+1}}\left(T_{s x+1}-T_{s x}\right),
$$

where $S_{x, x+1}$ and $d_{x, x+1}$ are respectively the surface and the distance between the centers of the solids of the zones $x$ and $x+1$ and $\lambda$ is the monolith conductive coefficient,

- gas mass transfer between two zones:

$$
Q_{g x, x+1}=\dot{m}_{g} C_{v}\left(T_{g x+1}-T_{g x}\right) .
$$

\subsection{Conversion of pollutant emissions}

The solids of the zones can receive heat from the exothermic chemical reactions of pollutant emission conversion. For each zone $x$ and each pollutant species $i \in\left\{C O, H C, N O_{X}\right\}$, the conversion reaction heat is given by:

$$
Q_{x i}=a_{i} \dot{m}_{x \text { in } i} \eta_{T i}\left(T_{s x}\right) \eta_{q}\left(t_{r x}\right),
$$

where $a_{i}$ is the conversion heat coefficient, $\eta_{T i}$ and $\eta_{q}$ are the conversion efficiency functions with respect to the temperature and residence time $t_{r x}=\frac{m_{g x}}{\dot{m}_{g}}$, and $\dot{m}_{x i n i}$ the entering pollutant flow rate (with, for the first zone, $\dot{m}_{1 \text { in } i}=\dot{m}_{\text {exh } i}$ ).

As represented on Fig. 1, the hotter the $3 \mathrm{WCC}$ is, the
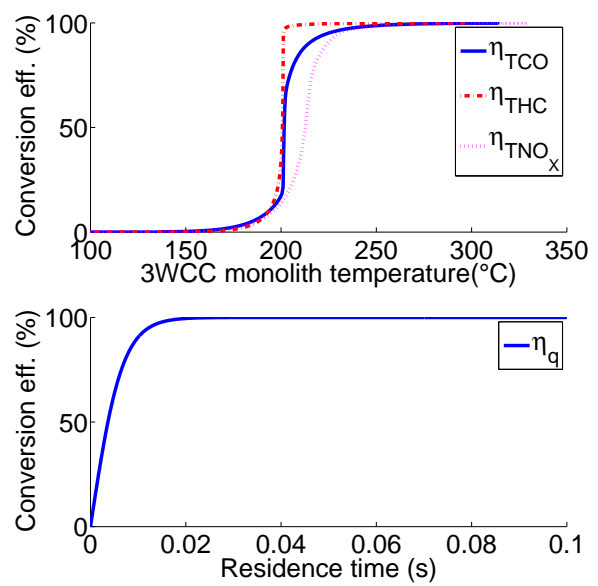

Fig. 1. Conversion efficiency functions with respect to temperature (top) and residence time (bottom)

better the conversion efficiencies are. And at low residence times (high exhaust gas flow rate), the conversion falls.

The flow rate of pollutant $i$ leaving zone $x, \dot{m}_{x \text { out } i}$, can be computed according to $\eta_{T i}$ and $\eta_{q}$ with:

$$
\dot{m}_{x \text { out } i}=\dot{m}_{x \text { in } i}\left(1-\eta_{T i}\left(T_{s x}\right)\right)\left(1-\eta_{q}\left(t_{r x}\right)\right) \text {. }
$$

But this modeling is not sufficient because of the complexity of the chemical conversion mechanisms and the flow rate/monolith temperature crossing effects on conversion. To overcome this problem, global $3 \mathrm{WCC}$ conversion efficiencies $\eta_{3 W C C} i$ are mapped with respect to the monolith temperature at the center of the $3 \mathrm{WCC}, T_{s X}$, and the exhaust gas flow rate, $\dot{m}_{g}$, from test bench experiments.

Fig. 2 shows the $C O$ conversion efficiency map, where the inputs have been normalized for confidentiality. This conversion map is more precise than the two functions $\eta_{T C O}$ and $\eta_{q}$ used in (8), represented in Fig. 1.

Then the flow rate at the $3 \mathrm{WCC}$ exit for pollutant $i$, $\dot{m}_{3 W C C}$, can be estimated by:

$$
\dot{m}_{3 W C C i}=\dot{m}_{e x h i}\left(1-\eta_{3 W C C i}\left(T_{s X}, \dot{m}_{g}\right)\right) .
$$

Note that (7) and (8) are used to determine the evolution of the $3 \mathrm{WCC}$ temperatures $T_{s x}$, particularly $T_{s X}$, which in turn is used in (9) to compute the $3 \mathrm{WCC}$ conversion efficiencies. 


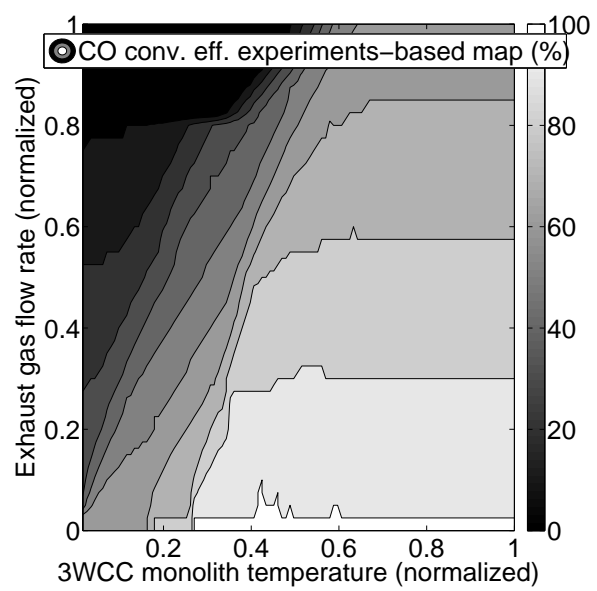

Fig. 2. Test bench experiments-based $C O$ conversion efficiency map

\subsection{Variables and parameters}

We now summarize the variables and parameters involved in the $3 \mathrm{WCC}$ model presented above, the rest of the variables being internal states:

- model inputs: engine exhaust gas temperature $T_{g}$, gas flow rate $\dot{m}_{g}$, and pollutant flow rates $\dot{m}_{e x h i}$,

- model output: 3WCC exit pollutant flow rates $\dot{m}_{3 W C C i}$,

- model parameters deduced from the $3 \mathrm{WCC}$ physical characteristics: $m_{s x}, V_{g x}, S_{s g}, S_{x x+1}, d_{x x+1}$,

- experiment-based maps: global efficiencies of the 3WCC conversion $\eta_{3 W C C}$,

- two groups of model parameters which are to be identified from different experiments: on one hand, the thermal coefficients, i.e. the specific heat capacities $C_{v}, C_{p}$, convective coefficient $c_{c o n v}$, monolith conductive coefficient $\lambda$; on the other hand, the conversion heat coefficients $a_{i}$.

\section{IDENTIFICATION AND VALIDATION}

The test bench is based on a 3-cylinder gasoline engine with its associated 3WCC. The monolith is a one-block ceramic substrate; other main characteristics are confidential. The most important measured variables are: engine exhaust gas temperature $T_{g}$, fuel consumption and Airfuel Ratio (AFR) allowing estimation of the engine gas flow rate $\dot{m}_{g}$, engine pollutant flow rates $\dot{m}_{e x h i}, 3 \mathrm{WCC}$ exit pollutant flow rates $\dot{m}_{3 W C C} i$, and $3 \mathrm{WCC}$ monolith temperatures at different points.

Two types of experiments were carried out:

- cooling phases applied on the hot 3WCC to identify the thermal coefficients,

- driving cycle-like phases to identify the conversion heat coefficients $a_{i}$ and to validate the model.

\subsection{Thermal behavior identification}

The cooling phases are applied when, after regular operation, the engine is operating without combustion. The hot $3 \mathrm{WCC}$ is crossed by a cold air flow rate without pollutant emissions to convert $\left(Q_{x i}=0\right.$ in $\left.(7)\right)$. Thermocouples are regularly positioned along the longitudinal axis of the $3 \mathrm{WCC}$, at the center of the radial zones. Other zones are considered between the thermocouple locations to simulate the monolith thermal dynamics. Fig. 3 shows the measured and estimated temperatures during a cooling phase with 3 thermocouples and 3 corresponding zones. This experiment shows that a $3 \mathrm{WCC}$ multi-0D modeling is sufficient to obtain the main monolith thermal dynamics.

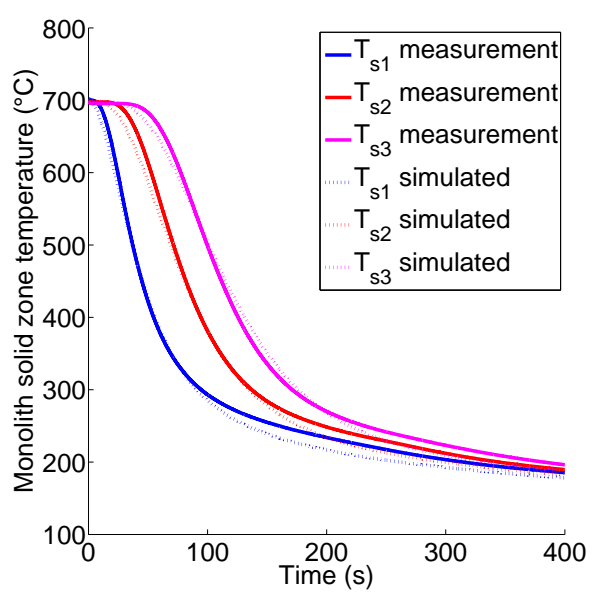

Fig. 3. Measured and estimated temperatures during a cooling phase with 3 thermocouples

The identified parameters, obtained by minimizing the Sum of Squared Errors between measured and estimated temperatures, are given in table 1 .

Table 1. Identified thermal coefficients

\begin{tabular}{cc} 
Coefficient & Value \\
\hline$C_{v}$ & $1000 \mathrm{~J} / \mathrm{m}^{3} \cdot \mathrm{K}$ \\
$C_{p}$ & $1070 \mathrm{~J} / \mathrm{kg} \cdot \mathrm{K}$ \\
$c_{\text {conv }}$ & $4000 \mathrm{~W} .^{2} / \mathrm{k}$ \\
$\lambda$ & $1 \mathrm{~W} \cdot \mathrm{m} / \mathrm{k}$ \\
\hline
\end{tabular}

\subsection{Conversion heat coefficients}

In this experiment, the $3 \mathrm{WCC}$ is crossed by the engine exhaust gas of a vehicle following a Worldwide harmonized Light vehicles Test Cycle (WLTC). A five-zones model was chosen as a compromise between model simplicity and accuracy of the results. The identified heat conversion coefficients are given in table 2 .

Table 2. Pollutant conversion heat coefficients

\begin{tabular}{cc} 
Coefficient & Value \\
\hline$a_{C O}$ & $10.000 \mathrm{~kJ} / \mathrm{kg}$ \\
$a_{H C}$ & $12.000 \mathrm{~kJ} / \mathrm{kg}$ \\
$a_{N O_{X}}$ & $40.000 \mathrm{~kJ} / \mathrm{kg}$ \\
\hline
\end{tabular}

The results in table 3 give the relative errors in $\%$ between the estimated and measured pollutant emissions, cumulated over the cycle.

Fig. 4 shows the measured $T_{s X}$ and simulated $\hat{T}_{s X}$ monolith temperatures at the center of the $3 \mathrm{WCC}$, and the cumulative pollutant emissions, expressed in relative values. 
Table 3. Pollutant emission relative errors (\%)

\begin{tabular}{cc} 
Pollutant & Relative error $(\%)$ \\
\hline$C O$ & -2 \\
$H C$ & -6 \\
$N O_{X}$ & -18 \\
\hline
\end{tabular}
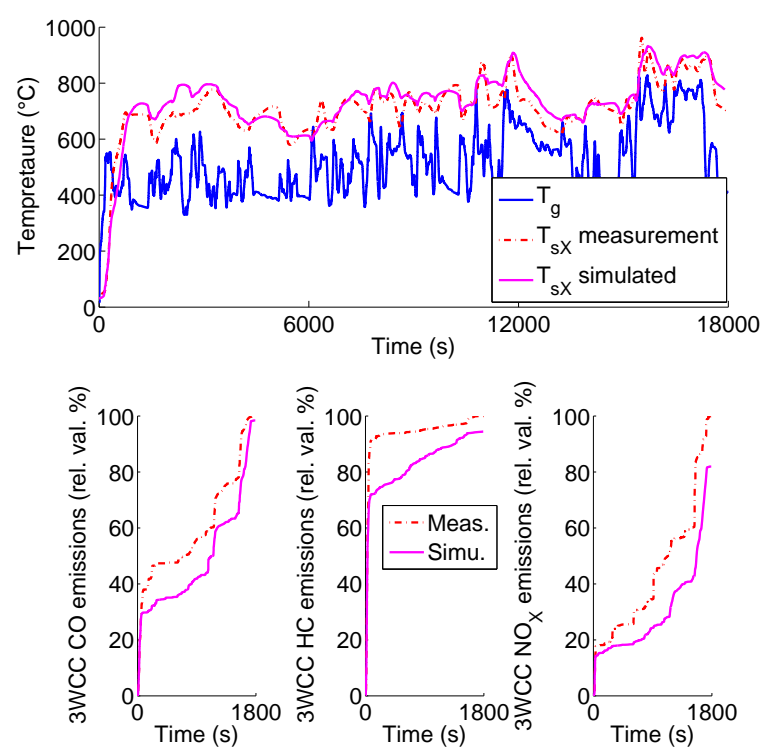

Fig. 4. Engine exhaust gas temperature $T_{g}$, measured $T_{s X}$ and simulated $\hat{T}_{s X}$ temperatures (top) and cumulative pollutant emissions relative values (bottom) during a WLTC

The corresponding Root Mean Square Error (RMSE) for the main temperature $T_{s X}$ is $63^{\circ} C$. The model gives estimated pollutant emissions smaller than the measured ones, particularly at the beginning of the simulation. This is due to the estimation of the temperature $T_{s X}$. As $\hat{T}_{s X}>T_{s X}$ at the beginning, the conversion efficiency is better (see Fig. 1), so the pollutant emissions are reduced. Nevertheless, the main trends are reproduced by the model.

Other WLTC-like phases (Valid.1 and Valid.2) were carried out to validate the model. Results are given in table 4. Globally the model can accurately predict the pollutant emissions. Again, the biggest relative value, in table 4 , is due to the strong impact of $T_{s X}$ estimation during the first seconds, where a small deviation can lead to a large conversion efficiency deviation at low $3 \mathrm{WCC}$ temperatures. These model pollution deviations are not problematic because the model will be used to compare different energy management strategies with a reference and to evaluate the potential pollution reduction of the pollution constraint.

Table 4. Validation results

\begin{tabular}{ccccc} 
& $C O$ & $\begin{array}{c}H C \\
\text { rel.val. }(\%)\end{array}$ & $N_{X}$ & $\begin{array}{c}T_{s X} \\
\text { RMSE in }{ }^{\circ} C\end{array}$ \\
\hline Valid.1 & 0 & 43 & 3 & 67 \\
Valid.2 & -10 & 6 & -30 & 80 \\
\hline
\end{tabular}

\section{OPTIMAL ENERGY MANAGEMENT}

Next the multi-0D five-zones 3WCC model is integrated in the high fidelity gasoline $\mathrm{HEV}$ powertrain model which is able to generate the $3 \mathrm{WCC}$ model inputs. The HEV is a parallel mild-hybrid vehicle with the electrical machine connected to the engine by a belt (Fig. 5). This

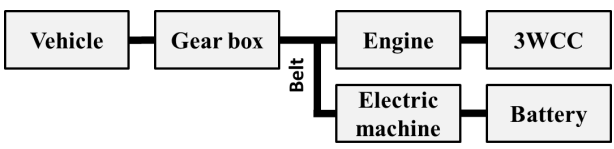

Fig. 5. Mild-hyrbid architecture

architecture allows regenerative braking, hybrid and zeroemissions vehicle (ZEV) modes. Due to architecture during the $\mathrm{ZEV}$ mode, the engine injection is cut off and the electrical machine produces power, keeping the engine rotating. Then during the $\mathrm{ZEV}$ phases the gas flow rate entering in the $3 \mathrm{WCC}$ is positive and cools the monolith.

\subsection{Torque split control}

The driver tracks the driving cycle speed by the accelerator and brake pedals. The requested torque $T_{0}(t)$ at the input of the gear-box can be deduced from these requests, by taking into account different gear-box and transmission ratios and efficiencies. In this work, the gear-box ratios are imposed and not optimized. This requested torque can be supplied by the engine or by the electrical machine:

$$
T_{0}(t)=T_{\text {elec }}(t)+T_{\text {eng }}(t),
$$

where $T_{\text {elec }}(t)$ and $T_{\text {eng }}(t)$ are respectively the electrical and engine torques expressed in the crankshaft referential. So, the energy management strategies use a torque split variable $u(t)$ representing the electrical part of the traction:

$$
u(t)=\frac{T_{e l e c}(t)}{T_{0}(t)} .
$$

Depending on the values of the torque split $u(t)$ and requested torque $T_{0}(t)$, the vehicle is operated in different modes: electrical traction (Zero Emissions Vehicle), boost, pure thermal traction, and recharging mode.

The goal of the energy management strategy is to determine the control variable $u(t)$ firstly by minimizing the fuel consumption, secondly with a pollutant constraint.

\subsection{Fuel consumption minimization}

The HEV model is simplified by considering a simple internal resistance model of the battery SOC dynamics:

$$
S \dot{O} C(t)=f(S O C(t), u(t)) \text {. }
$$

The off-line strategy has to minimize the performance index:

$$
\begin{array}{r}
J_{\text {fuel }}(S O C(t), u(t))=\phi\left(S O C\left(t_{f}\right), t_{f}\right) \\
+\int_{t_{0}}^{t_{f}} \dot{m}_{\text {fuel }}(u(t), t) d t,
\end{array}
$$

where $\dot{m}_{f u e l}(u(t), t)$ is the fuel consumption, given from a map, and $\phi\left(S O C\left(t_{f}\right), t_{f}\right)$ is a final battery State Of Charge (SOC) sustaining constraint:

$$
\phi\left(S O C\left(t_{f}\right), t_{f}\right)=\left\{\begin{array}{l}
0 \text { if } S O C\left(t_{f}\right)=S O C\left(t_{0}\right), \\
\infty \text { else }
\end{array}\right.
$$


The Hamiltonian

$$
\begin{aligned}
H\left(S O C(t), u(t), \lambda_{1}(t), t\right)= & \dot{m}_{f u e l}(u(t), t) \\
& +\lambda_{1}(t) S \dot{O} C(t)
\end{aligned}
$$

is introduced, where $\lambda_{1}(t)$ is the co-state associated to the SOC state, respecting

$$
\dot{\lambda}_{1}^{T}(t)=-\frac{\partial H\left(S O C(t), u(t), \lambda_{1}(t), t\right)}{\partial S O C} .
$$

According to the Pontryagin Minimum Principle (PMP), the optimal control $u^{*}(t)$ minimizing (13) is found as

$$
u^{*}(t)=\underset{u \in E}{\operatorname{argmin}} H\left(S O C(t), u(t), \lambda_{1}(t), t\right),
$$

where $E$ is the admissible control space taking into account the constraints on the HEV components.

In the case of an $\mathrm{HEV}$, and for a given driving cycle, the assumption:

$$
\dot{\lambda}_{1}^{T}(t)=0
$$

has very little influence on the fuel consumption since the state dynamics $S \dot{O} C(t)$ does not depend on the state $S O C(t)$. In this case, $\lambda_{1}$ is taken constant and a simple binary search can yield the value that minimizes HEV fuel consumption and ensures charge sustaining.

\subsection{Pollution consideration}

To consider pollution, we define an augmented performance index:

$$
\begin{array}{r}
J_{\text {mixed }}\left(S O C(t), T_{s X}(t), u(t)\right)=\phi\left(S O C\left(t_{f}\right), t_{f}\right) \\
+\int_{t_{0}}^{t_{f}} \dot{m}_{\text {mixed }}\left(u(t), T_{s X}(t), t\right) d t,
\end{array}
$$

where $\dot{m}_{\text {mixed }}$ is a mixed pollution/fuel consumption flow rate defined by:

$$
\begin{array}{r}
\dot{m}_{\text {mixed }}\left(u(t), T_{s X}(t), t\right)=\dot{m}_{\text {fuel }}(u(t), t) \\
+\alpha \sum_{i} \frac{\dot{m}_{3 W C C i}\left(u(t), T_{s X}(t), t\right)}{s t d_{i}},
\end{array}
$$

where the $\dot{m}_{3 W C C} i$ are defined in (9) with $i \in\left\{C O, H C, N O_{X}\right\}$ and the $s t d_{i}$ are the acceptable pollution limits of the Euro $\mathrm{V}$ standard.

To minimize (19), the 3WCC temperature dynamics:

$$
\dot{T}_{s X}(t)=g\left(T_{s X}(t), u(t)\right)
$$

is considered in the PMP resolution. $T_{s X}(t)$ is the monolith center temperature used in (9) to find the pollutant flow rate at the $3 \mathrm{WCC}$ exit. The $3 \mathrm{WCC}$ temperature dynamics can be analytically calculated from (1), (2), (3) and (9) but in this study, because of computation time considerations, a simplified form is chosen to define the Hamiltonian:

$$
\begin{array}{r}
H\left(S O C(t), T_{s X}(t), u(t), \lambda_{1}(t), \lambda_{2}(t), t\right) \\
=\dot{m}_{\text {mixed }}(u(t), t)+\lambda_{1}(t) S \dot{O} C(t)+\lambda_{2}(t) \dot{T}_{s X}(t) .
\end{array}
$$

As previously, $\lambda_{1}(t)$, taken constant, is determined by binary search to ensure charge sustaining. The second costate $\lambda_{2}(t)$ evolves as:

$$
\dot{\lambda}_{2}^{T}(t)=-\frac{\partial H\left(S O C(t), T_{s X}(t), u(t), \lambda(t), t\right)}{\partial T_{s X}},
$$

according to the PMP, giving a closed form:

$$
\lambda_{2}(t)=\lambda_{20} \exp ^{A(t)},
$$

where $A(t)$ is a function deduced from (23) with:

$$
A(t)=a t-b(u(t))
$$

where $a$ is a constant and $b$ a function deduced from the simplified form chosen to approximate (21). Finally, the optimal control $u^{*}(t)$ minimizing (19) can be found by minimizing (22):

$$
u^{*}(t)=\underset{u \in E}{\operatorname{argmin}} H\left(S O C(t), T_{s X}(t), u(t), \lambda_{1}(t), \lambda_{2}(t), t\right) .
$$

with $\lambda_{2}(t)$ computed with (24).

The tuning of the strategy is possible with 2 parameters: $\alpha$ defined in (20) and $\lambda_{20}$ defined in (24). In [Michel et al. (2014)] it was proven that tuning $\alpha$ with $\lambda_{20}=0$ gives better results than tuning $\lambda_{20}$. Choosing $\lambda_{2}(t)=0$ implies constraining pollution, without any constraints on the $3 \mathrm{WCC}$ temperature $T_{s X}$. All results presented below were obtained with $\lambda_{20}=0$ which corresponds to the second strategy described in the introduction.

\section{RESULTS}

The fuel consumption minimization strategy was implemented in the HEV model supervisory control and the corresponding optimal control $u^{*}(t)$ (17) was applied to the HEV model. Next variations of $\alpha$ in (20) make it possible to explore trade-offs between pollution and fuel consumption when applying $u^{*}(t)(26)$ to the HEV.

The simulation results are charge sustaining constrained, with a binary search of the constant $\lambda_{1}$. Table 5 gives, for different fuel consumption/pollution compromises $\alpha$, the relative variations in $\%$ of the fuel consumption and pollutant emissions, cumulated on a WLTC, w.r.t the reference, where only the fuel consumption is minimized. This table shows good results of the pollution constrained optimal energy management strategy. As the constraint parameter $\alpha$ increases, the pollution decreases with little impact on fuel consumption..

Table 5. Relative variations in \% (WLTC)

\begin{tabular}{ccccc} 
& Fuel Cons. & $C O$ & $H C$ & $N O_{X}$ \\
\hline$\alpha=0.2$ & 0.06 & -7.7 & -1.4 & -3.2 \\
$\alpha=0.4$ & 0.17 & -11.4 & -3.2 & -9.4 \\
$\alpha=0.5$ & 0.18 & -11.8 & -4.1 & -10.3 \\
$\alpha=0.6$ & 0.25 & -12.1 & -5.6 & -10.8 \\
\hline
\end{tabular}

Fig. 6 shows simulation trajectories of the $S O C(t)$ and $T_{s X}(t)$ states for the reference, $\alpha=0.2$ and $\alpha=0.6$ compromises. $\alpha=0.6$ is the largest admissible value. Greater values drain the battery and cross the health boundary by the SOC. In Fig. 6, it can be seen that the larger the compromise parameter $\alpha$ is, the more slowly the $3 \mathrm{WCC}$ is heated. This can be expressed as smart heating: at the beginning of the driving cycle, to produce less pollution when heating the $3 \mathrm{WCC}$, the electrical machine $\left(T_{\text {elec }}>0\right)$ helps the engine to produce the requested torque $T_{0}(t)$. The effect is lower pollutant emissions during the $3 \mathrm{WCC}$ heating as seen in Fig. 7. The electrical machine uses the decrease in the battery $S O C(t)$ which is caught up later during recharging phases. Larger engine exhaust emissions are produced but the 3WCC conversion efficiencies are faster close to $100 \%$, reducing the $3 \mathrm{WCC}$-vehicle emissions. From these observations, online heuristic strategies will be surely derived. 

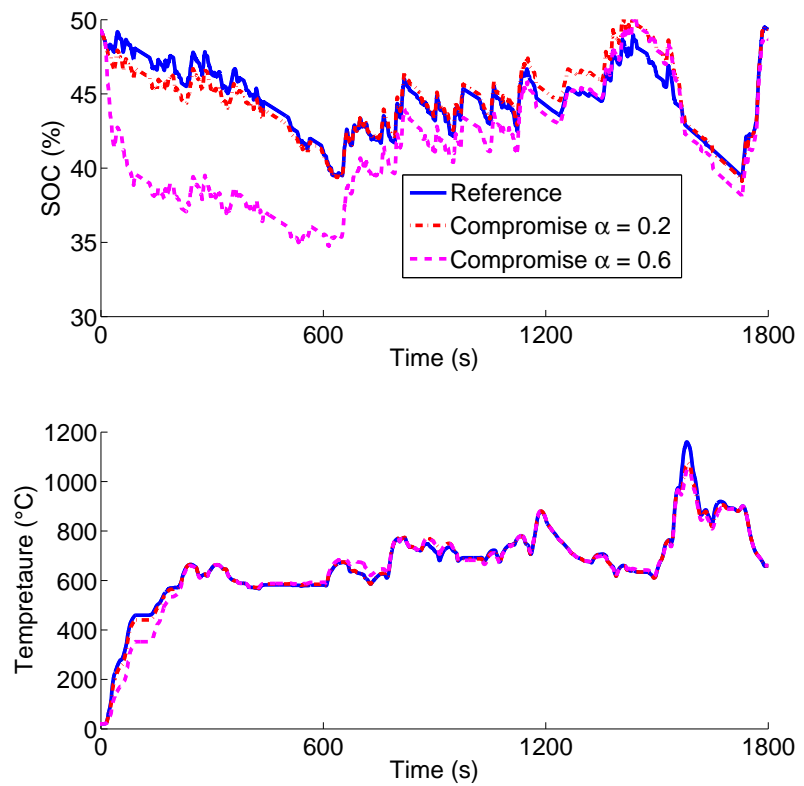

Fig. 6. States $S O C(t)(t o p)$ and $T_{s X}(t)$ (bottom) trajectories
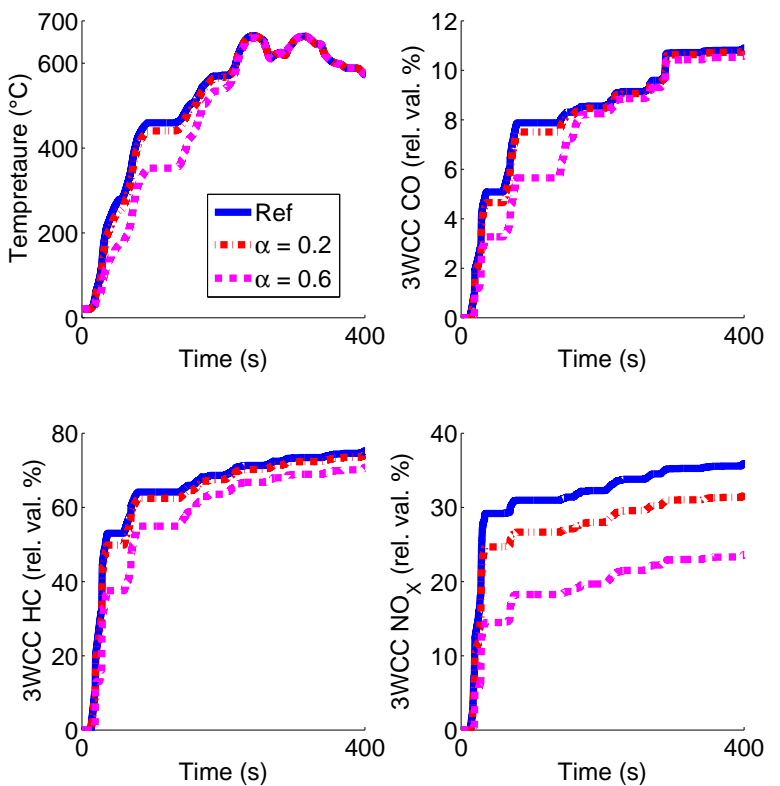

Fig. 7. States $T_{s X}(t)$ (top left) trajectories, $C O$ (top right), $H C$ (bottom left), and $N O_{X}$ (bottom right) cumulative relative values

\section{CONCLUSION}

A simple 3WCC multi-0D model has been built from physical equations, integrating the 3WCC temperature dynamics and a pollutant emission conversion map. Thermal parameters were identified from hot 3WCC cooling experiments and chemical parameters from WLTClike phases. The validated model involves complexity and performances suitable to be integrated in a high fidelity gasoline-HEV powertrain model.
Next, a pollutant constrained optimal energy management was derived from the Pontryagin Minimum Principle. A second state variable, the 3WCC temperature, was introduced in the optimization problem. The approach allows the joint minimization of pollution and fuel consumption with only one parameter to tune, by considering all the standardized pollutant emissions.

The proposed strategy reduces the $C O$ and $N O_{X}$ emissions by around $10 \%$ and the $H C$ emissions by around $5 \%$ with a minor fuel consumption increase of $0.25 \%$.

Using a complex HEV model shows the feasibility of integrating a pollution constraint in on-line energy management. For the future more stringent standards, the pollution constrained energy management strategy will be a costless way to take pollution into account.

\section{REFERENCES}

Bellman, R. (1956). Dynamic Programming and the Smoothing Problem. Management Science, 3(1), 111113.

Chasse, A., Corde, G., Del Mastro, A., and Perez, F. (2010). Online optimal control of a parallel hybrid with after-treatment constraint integration. In IEEE Vehicle Power and Propulsion Conf. (VPPC).

Grondin, O., Thibault, L., Moulin, P., Chasse, A., and Sciarretta, A. (2011). Energy management strategy for Diesel hybrid electric vehicle. In IEEE Vehicle Power and Propulsion Conf. (VPPC).

Kum, D., Peng, H., and Bucknor, N. (2008). Modeling and control of hybrid electric vehicles for fuel and emission reduction. In ASME 2008 Dynamic Systems and Control Conference, 553-560.

Michel, P., Charlet, A., Colin, G., Chamaillard, Y., Nouillant, C., and Bloch, G. (2012). Energy management of $\mathrm{HEV}$ to optimize fuel consumption and pollutant emissions. In 11th Symp. on Advanced Vehicle Control (AVEC 2012).

Michel, P., Charlet, A., Colin, G., Chamaillard, Y., Nouillant, C., and Bloch, G. (2013). Pollution constrained optimal energy management of a gasoline-HEV. In 11th Int. Conf. on Engines and Vehicles (ICE 2013).

Michel, P., Charlet, A., Colin, G., Chamaillard, Y., Nouillant, C., Bloch, G., et al. (2014). 3WCC temperature integration in a gasoline-hev optimal energy management strategy. Advances in Mechanical Engineering.

Millo, F., Rolando, L., and Servetto, E. (2011). Development of a Control Strategy for Complex Light-Duty Diesel-Hybrid Powertrains. SAE Technical Paper 201124-0076.

Pontryagin, L.S. (1962). The Mathematical Theory of Optimal Processes. John Wiley.

Serrao, L., Sciarretta, A., Grondin, O., Chasse, A., Creff, Y., Di Domenico, D., Pognant-Gros, P., Querel, C., and Thibault, L. (2013). Open issues in supervisory control of hybrid electric vehicles: A unified approach using optimal control methods. Oil Gas Sci. Technol. - Rev. IFP Energies Nouvelles, 68(1), 23-33.

Tate, E.D., Grizzle, J., and Peng, H. (2010). SP-SDP for fuel consumption and tailpipe emissions minimization in an EVT hybrid. Control Systems Technology, IEEE Transactions on, 18(3), 673-687. 